\title{
DERECHO PROPIO E IDENTIDAD CULTURAL EN NIÑOS AYMARAS. UNA ZONA DE COMPLEJIDAD JURÍDICA
}

\author{
OWN LAW AND CULTURAL IDENTITY IN CHILDREN AYMARAS: \\ AN AREA OF LEGAL COMPLEXITY
}

\begin{abstract}
Álvaro Espinoza Collao*
Se analiza el ejercicio de ponderación judicial realizado por los tribunales nacionales e internacionales frente a conflictos que involucran a niños indígenas. En este contexto se desarrolla la relación entre las variables identidad cultural, Derecho propio y niños indígenas. Se estudian los fundamentos de las sentencias en la estructura interamericana de Derechos Humanos identificando los estándares jurídicos que fijan parámetros para la función judicial interna. Finalmente se consideran casos judiciales nacionales que involucran a niños de la etnia indígena aymara del norte de Chile. Se registran criterios variables de interpretación normativa al momento de aplicar la costumbre para resolver conflictos judiciales de la población aymara, impidiendo que se cumplan los fines de la norma y comprometiendo la responsabilidad internacional del Estado frente al incumplimiento de los compromisos internacionales vigentes.
\end{abstract}

Palabras claves: Niños Aymaras, Jurisprudencia, derecho a la identidad cultural.

The judicial weighting exercise carried out by national and international courts against conflicts involving indigenous children is analyzed. In this context, the relationship between the variables of cultural identity, own law and indigenous children is developed. The foundations of the judgments in the inter-American structure of Human Rights are studied, identifying the legal standards that set parameters for the internal judicial function. Finally, national judicial cases involving children of the Aymara indigenous ethnic group from northern Chile are considered. Variable criteria of normative interpretation are recorded when applying the custom to resolve judicial conflicts of the Aymara population, preventing the purposes of the norm from being fulfilled and compromising the international State's responsibility for non-compliance with current international commitments.

Key words: Aymara children, Jurisprudence, right to cultural identity.

\section{Introducción}

Uno de los rasgos propios de la posmodernidad jurídica es el quiebre del conjunto de paradigmas de la antigua modernidad, entre estos los valores propios de la Ilustración que plasmaban la ideas de racionalidad, universalidad e igualdad. Estas pasarán a considerarse como transitorias de reglas sustentadas en particularidades fragmentarias, como un ethos que pondera las diferencias de las minorías desde una pluralidad jurídica (Pérez, 2007). En este sentido, la doctrina describe el pluralismo jurídico como un factor propio de esta postmodernidad (Santos, 1988; De Trazeignes, 2018).
Este paradigma impondrá la necesidad de insertar en los sistemas jurídicos el derecho de autodeterminación y como efecto la aplicación del Derecho propio indígena, desarrollando un proceso de traducción de la expresión jurídica de estos colectivos. En nuestra realidad el acogimiento del pluralismo jurídico solo será recepcionado parcialmente, manteniendo estructuras normativas contrarias en cuestiones fundamentales como la inexistencia de la judicatura propia y el reconocimiento constitucional. Por tanto, este deber será ejecutado por órganos judiciales generales, quienes deberán identificar un Derecho propio, luego interpretarlo y finalmente ejecutarlo respetando el sentido de identidad cultural.

\footnotetext{
* Universidad de Tarapacá, Departamento de Ciencias Sociales y Jurídicas. Iquique, Chile. Correo electrónico: alvaro2677@gmail.com. Dirección postal: Ricardo Fernández 2757, Iquique.
} 
Este ejercicio reflejará distintas tensiones, primero la existencia de un diálogo de adecuación entre instituciones que derivará en una constante filtración de criterios de raíz occidental distantes de los fines que promueven la norma especial indígena. Dando lugar a aquello que Bobbio (2007) denomina como antinomias teleológicas cuando existe contradicción entre norma que prescribe el medio para ejecutar un fin y la que prescribe el fin; de manera que si se aplica la norma no se cumple el fin y viceversa.

Luego se revela un problema de interpretación al pretender identificar la norma propia por parte de una judicatura ajena a los valores que fundan dicha expresión jurídica, en esta tarea los jueces se apoyarán con patrones más bien difusos en áreas como la antropología o la historia. Este escenario propiciará sentencias diversas generando contrapuntos en la forma como se fija el Derecho, acudiendo a conceptos como herramientas de intersubjetividad que en su comunicación de una disciplina a otra se resignifican, siendo dinamizados y convertidos en instrumentos de otros sujetos (Cruz, 2019). Este ejercicio finalmente privará al Derecho de uno de sus fines elementales como es la seguridad o certeza jurídica.

Desde este espacio, proponemos identificar la relación entre identidad cultural, Derecho propio y niños indígenas como variables que dan cuenta de una tríada inserta en la normativa vigente. Luego analizaremos la ponderación en clave intercultural que realiza la estructura interamericana de Derechos Humanos, espacio de relevancia debido al establecimiento de estándares jurídicos que deben ser considerados por la judicatura nacional al momento de resolver los conflictos internos. Finalmente, examinaremos dos casos resueltos ante los tribunales nacionales que exhiben disparidades de criterio al conjugar todas las variables expuestas.

En cuanto a la metodología del trabajo, proponemos un estudio dogmático para explorar la estructura normativa vigente y sus contrapuntos como expresión del Derecho vigente en materia de infancia indígena aymara en el territorio nacional. A continuación desarrollaremos un análisis jurisprudencial de sentencias nacionales e internacionales que nos permiten identificar de una perspectiva realista los mecanismos a los que acuden los tribunales para resolver estos conflictos, identificando diferencias que dan cuenta de costumbres difusas como consecuencia de una dinámica de constantes.

\section{Derecho propio indígena como herramienta de reconocimiento de la identidad cultural en niños indígenas}

Las culturas indígenas no fueron consideradas desde las perspectivas de sus particularidades en la construcción de las naciones latinoamericanas, en contrario, las élites independentistas acabarán con la organización estructurada en estatus de las sociedades coloniales, incorporando a todos los ciudadanos bajo las premisas de la igualdad ilustrada estableciendo una política de asimilación e integración. Este criterio persistirá en nuestra realidad jurídica hasta nuestros días, frente a la ausencia de reconocimiento constitucional de la diversidad étnica.

En contrario, la existencia actual de una estructura internacional de Derechos Humanos relevará lo indígena desde sus particularidades, reincorporando al individuo en su calidad de sujeto de Derecho. En este sentido, el mandato soberano de respetar este espacio de alteridad normativa se confrontará con el desafío de identificar un Derecho propio para garantizar la identidad cultural. Entonces, la igualdad en los derechos de las personas indígenas incluiría relevar la necesidad de un Derecho propio como elemento esencial para que exista una comunidad propia (Clavero, 2009: 110).

Esto sitúa el objeto de análisis de la praxis jurídica en una cuestión de eficacia, trasladando el centro de la discusión a lo empírico-funcional, es decir, a cómo opera efectivamente la norma en la población. En este sentido, Diez Picazo (1993) explica que el Derecho ante todo es un conjunto de experiencias vividas expresadas como decisiones que resuelven conflictos de intereses al interior de una comunidad. En este ejercicio los tribunales determinarán qué conductas encajan con el estándar de la costumbre jurídica, ponderando entre un acto ejecutado y un modelo ideal no descrito, cuestión que no resulta diferente a la dinámica judicial global, salvo que en el Derecho no indígena la existencia de órganos y procedimientos formales fijen la norma autogenerando el sistema jurídico en cada tiempo.

Así como hemos indicado en otros estudios (Espinoza, 2020), una consideración especial 
conlleva la zona en análisis, en cuanto la población aymara del norte de Chile ha atravesado históricamente por constantes transformaciones, desde el impacto del proceso de conquista y la instalación del modelo colonial; los efectos del modelo económico de exportación de guano y salitre en tiempos del Perú desde mediados del siglo XIX; el proceso de chilenización a inicios del siglo XX (González, 2002), y los procesos migratorios a las grandes ciudades, lo que determinan una manera particular de vivir en sociedad (Gunderman, 2019). Todas estas variables actúan modelando nuevos patrones culturales cada una con su impacto en lo consuetudinario.

La diversidad cultural se inserta en la teoría del Derecho mediante la consagración internacional del Derecho a la identidad cultural. Resulta posible discutir, en contrario, mediante el alcance del derecho a la dignidad humana consagrado a nivel constitucional que, como indica Cea, se conforma como la base de un conjunto de derechos configurativos de la identidad única e irrepetible de cada sujeto libre... (Cea, 2012: 44). Postulamos que esta tesis en materia indígena no alcanzaría la dimensión de certeza jurídica de los instrumentos jurídicos creados especialmente para este fin.

Este Derecho a la identidad cultural consistiría un reconocimiento formal de una alteridad intersubjetiva que al insertarse en la estructura jurídica implicaría un mutuo reconocimiento a desarrollarse en los valores culturales que libremente elija cada persona (Del Real, 2013). En el Derecho la identidad cultural se expresaría como un mandato abierto sujeto a la interpretación que den los tribunales. En esta línea, Haberle (2006), destaca que este ejercicio solo puede tener éxito en un diálogo de carácter interdisciplinar, es decir, mediante el auxilio de otras disciplinas como la Historia, la Antropología u otras afines. Como indica Fernández (2000), desde el relato indígena los derechos se sustentan en el pasado, así la historicidad crea la legitimidad jurídica como resultado de la conciencia histórica.

La consagración positiva del Derecho a la identidad cultural se remonta al Pacto de Derechos Civiles y Políticos de 1966 y su artículo 27 que establece el deber de los Estados en donde existan minorías étnicas de no negarles el derecho "a tener su propia vida cultural, a profesar y practicar su propia religión y a emplear su propio idioma" (PDCP, 1966: art. 27). Posteriormente, este se insertará en un conjunto de instrumentos internacionales de carácter general, será el Convenio 169 de la Organización Internacional del Trabajo (Convenio), en su artículo $\mathrm{N}^{\circ} 2$, quien establecerá el deber del Estado de realizar las acciones para garantizar el derecho de los pueblos indígenas a su identidad cultural, costumbres y tradiciones. En su artículo $\mathrm{N}^{\circ} 8$ indica que al aplicarse la legislación nacional deberán tomarse debidamente en consideración sus costumbres o su derecho consuetudinario, estableciendo como límite el respeto por los Derechos Humanos reconocidos internacionalmente y los derechos fundamentales fijados en el orden interno.

Al pretender estudiar la identidad cultural desde la perspectiva de niños indígenas debemos necesariamente insertar otras variables. En general históricamente las sociedades humanas han dividido el proceso del desarrollo de las personas en fases, desde estas se fijan a su vez un catálogo de más o menos derechos. Actualmente en las sociedades occidentales la infancia es vista como una etapa de protección especial de la vida, esto en lo jurídico ha transitado desde una posición de objeto de Derecho hasta avanzado el siglo XX, a un sujeto de Derecho con particularidades.

Este paradigma normativo contrastará desde una perspectiva ontológica con la mirada de sociedades no occidentales respecto del lugar que ocupa la niñez. Estas diversidades han comenzado a ser atendidas dentro de estructuras jurídicas especiales insertando herramientas de resistencia formal frente a la asimilación. En la Convención de Derechos del Niño de 1989 se consagrará un bloque en materia de niñez indígena que permitirá reforzar su protección en la estructura normativa, favoreciendo el criterio de especialidad en caso de antinomias. En su artículo $8^{\circ}$ indica que: "Los Estados partes se comprometen a respetar el derecho del niño a preservar su identidad, incluidos la nacionalidad, el nombre y las relaciones familiares de conformidad con la ley sin injerencias ilícitas". Luego en su artículo 30 dispone que:

En los Estados en que existan minorías étnicas, religiosas o lingüísticas o personas de origen indígena, no se negará al niño que pertenezca a tales minorías o que sea indígena el derecho que le corresponde, en común con los demás miembros de su grupo, a tener su propia vida cultural, a 
profesar y practicar su propia religión, o a emplear su propio idioma.

La Organización de Naciones Unidas (ONU) ha indicado que esta norma reconoce la existencia de un derecho que no debe negarse, así todo Estado debe adoptar medidas positivas de protección, no solo contra los actos que pueda realizar mediante sus propias autoridades, sino respecto de cualquier persona (Comité de los Derechos del Niño de Naciones Unidas, 2009). En el mismo sentido, la Observación General $\mathrm{N}^{\mathrm{o}} 11$ denominada "Los niños indígenas y sus derechos en virtud de la Convención sobre los Derechos del Niño" del Comité de los Derechos del Niño de Naciones Unidas (2009), insta a los Estados a que adopten criterios fundados para la garantía de los derechos de los niños indígenas sobre la base de la Convención y de otras normas internacionales (Comité de los Derechos del Niño de Naciones Unidas, 2009: párr. 2).

La ley indígena nacional no se ocupa de manera particular acerca de la identidad cultural de los niños indígenas, solo trata aspectos aislados de la posesión notoria de la calidad de hijo que permiten una diferenciación en clave cultural de aplicación general. Sin embargo, establece criterios similares para todos los pueblos indígenas que habitan el territorio, distanciándose del sentido de respeto por la particularidad de la identidad cultural (Espinoza, 2016).

En definitiva, desde el análisis de la estructura internacional de derechos humanos es posible descifrar una garantía reforzada respecto de la niñez indígena con perspectiva de identidad cultural. Primero, una de carácter general como individuo perteneciente a una etnia indígena $\mathrm{y}$, otra, de protección especial asociada a la niñez con pertenencia cultural. Desde la perspectiva de técnica jurídica, esto funciona como garantía al momento de confrontar contrapuntos con otras normas favoreciendo la eficacia de su derecho a la identidad cultural y su Derecho propio.

\section{Los estándares interamericanos respecto de la identidad cultural en niños indígenas. La resignificación de la institucionalidad propia}

Hemos identificado la existencia de un mandato vinculante para el Estado emanado de los instrumentos internacionales de Derechos Humanos, este establece el deber de aplicar el Derecho propio indígena con enfoque de pertenencia cultural. Esto en el caso de niños indígenas derivaría de una doble fuente, como norma general asociada a la identidad cultural y de manera especial asociado a su carácter de sujeto especial (Valenzuela, 2016).

Este deber que hemos identificado como un efecto del acogimiento de la diversidad cultural que caracteriza el Derecho de nuestro tiempo, genera al momento de su cumplimiento diversos contrapuntos en la labor de los Tribunales. Varias causas contribuyen a este escenario: a) la inexistencia de una regulación orgánica de la costumbre indígena; b) la formación jurídica en un medio que tempranamente relegó la costumbre a un papel secundario bajo la imperatividad de la ley (Guzmán, 1987); y, c) una zona sujeta a constantes cambios socioculturales en la que está inserta la población aymara del norte de Chile.

En este contexto, los tribunales nacionales deberán realizar el ejercicio de reconocer un Derecho consuetudinario propio indígena para resolver los conflictos de esta población, propendiendo además respetar la institucionalidad y la identidad cultural en su ejercicio de ponderación. En esta línea, la Corte Interamericana de Derechos Humanos (CIDH) ha señalado que la identidad cultural es "un derecho humano fundamental y de naturaleza colectiva de las comunidades indígenas, que debe ser respetado en una sociedad multicultural, pluralista y democrática" (CIDH, 2017: 113).

Desde este enfoque, existe una jurisprudencia instaurada que reconoce el respeto a la identidad cultural asociado a la aplicación igualitaria de un Derecho propio, resaltando que este último se integra por sus valores, usos y costumbres desde una perspectiva de pertenencia cultural (CIDH, 2007, 2014). Así, ha aplicado las normas consuetudinarias incluso contra la ley, cuando esta última no resulta eficaz ni goza de reconocimiento en los sujetos normados, o planteando diferencias en su aplicación en cuanto a su extensión (CIDH, 1993).

Esta realidad normativa ha ampliado el ámbito de discusión a la eficacia de esta estructura internacional, en nuestra área la Convención Americana de Derechos Humanos (1969) establece la Comisión y la Corte Interamericana de Derechos Humanos como órganos encargados de 
dar protección y monitorear el cumplimiento de las obligaciones establecidas en dicho instrumento. En la actualidad la discusión se ha focalizado en el valor de las sentencias dictadas por estos tribunales y los mecanismos para otorgarle eficacia (Contesse, 2013).

En este contexto surge el denominado control de convencionalidad que impone a los órganos judiciales internos el deber de examinar la compatibilidad entre las normas nacionales, la Convención Americana y otros instrumentos del sistema interamericano, incluyendo la interpretación que realice la propia CIDH estableciendo estándares jurisprudenciales (Núñez, 2015). Nuestra Corte Suprema (2019) ha indicado que la magistratura interna deberá desarrollar ex oficio un control de equivalencia, lo que puede alcanzar la supresión de la norma interna.

En materia de niños indígenas o tribales la estructura interamericana de Derechos Humanos ha venido fijando distintos estándares que dan cuenta del alcance de la normativa vigente (Espinoza, 2017). En el caso del pueblo Aloeboetoe y otros con Surinam (1993), la Corte hará prevalecer el Derecho consuetudinario familiar de los maroons para definir quiénes serían los herederos beneficiarios de una indemnización de perjuicios, así considerará el carácter matrilineal y el régimen de poligamia propio de su estructura social, esto pese a la oposición del Estado de Surinam que en su defensa solicitó que no se reconociera carácter vinculante a su Derecho consuetudinario; y que se acudiera al concepto de familia occidental fijado en su Código Civil. La Corte indicará:

...[ ] las pruebas producidas permiten deducir que las leyes de Suriname sobre esa materia no tienen eficacia respecto de aquella tribu; sus integrantes las desconocen y se rigen por sus propias reglas y el Estado...[ ]. Además, los conflictos que ocurren en estas materias no son sometidos por los saramacas a los tribunales del Estado y la intervención de estos en las materias mencionadas, respecto de los saramacas, es prácticamente inexistente. Cabe señalar también que en este proceso Suriname reconoció la existencia de un derecho consuetudinario saramaca (CIDH, 1993: párr. 58).
En el caso Chitay Nech y otros con Guatemala (2010), la Corte resaltará el carácter reforzado de la protección a favor de los niños indígenas con especial mención a su identidad cultural, advirtiendo que:

...[ ] los Estados, además de las obligaciones que deben garantizar a toda persona bajo su jurisdicción, deben cumplir con una obligación adicional y complementaria definida en el artículo 30 de la Convención sobre los Derechos del Niño, la cual dota de contenido al artículo 19 de la Convención Americana, y que consiste en la obligación de promover y proteger el derecho de los niños indígenas a vivir de acuerdo con su propia cultura, su propia religión y su propio idioma (CIDH, 2010: párr. 168).

En el caso Masacres de Río Negro con Guatemala (2012) se asociará el concepto de identidad cultural de la niñez indígena con el territorio, destacando que:

... [ ] teniendo en cuenta que el desarrollo del niño es un concepto holístico que abarca el desarrollo físico, mental, espiritual, moral, psicológico y social, la Corte estima que para el desarrollo pleno y armonioso de su personalidad, los niños indígenas, de acuerdo con su cosmovisión, preferiblemente requieren formarse y crecer dentro de su entorno natural y cultural, ya que poseen una identidad distintiva que los vincula con su tierra, cultura, religión, e idioma (CIDH, 2012: párr. 144).

En Caso de la Comunidad indígena Xákmok Kásek con Paraguay (2010), la Corte vincula la identidad cultural con rituales y costumbres de niños indígenas indicando que:

...[ ] la pérdida de prácticas tradicionales, como los ritos de iniciación femenina o masculina y las lenguas de la Comunidad, y los perjuicios derivados de la falta de territorio, afectan en forma particular el desarrollo e identidad cultural de los niños y niñas de la Comunidad, 
quienes no podrán siquiera desarrollar esa especial relación con su territorio tradicional y esa particular forma de vida propia de su cultura si no se implementan las medidas necesarias para garantizar el disfrute de estos derechos (CIDH, 2010: párr. 263).

En definitiva, la Corte ha fijado estándares jurisprudenciales específicos vinculados a niñez indígena, estos son posibles de resumir a lo menos en: a) el reconocimiento a autogobernarse por su Derecho propio; b) el reconocimiento del derecho preferente a vivir de acuerdo con su identidad cultural y su propio idioma; c) el reconocimiento de un derecho preferente a vivir y desarrollarse en su medio natural y cultural directamente asociado a su tierra, cultura y religión; d) la pérdida de sus prácticas y ritos tradicionales vulnera su derecho a la identidad cultural.

\section{Dos casos y una ponderación judicial diversa}

Lo caracteriza en común al ejercicio judicial interno; es una ponderación bastante flexible que manifiesta una compleja diversidad tanto a la oportunidad como a la forma en que se aplica la costumbre para resolver asuntos de la población aymara. Esto se extiende desde la omisión absoluta, generalmente asociado al razonamiento de que un indígena incorporado a la urbanidad pierde su carácter de tal (Tribunal Oral en lo Penal Arica, 2010); también se observa una tendencia a interpretar lo consuetudinario bajo una óptica occidental (Corte de Apelaciones de Antofagasta, 2006).

Esta falta de homogeneidad en los criterios judiciales resalta la incerteza jurídica que debe enfrentar esta población en la resolución de sus conflictos, pese a la consagración de sus derechos en instrumentos positivos. De manera especial justifica la necesidad de una garantía efectiva de su identidad cultural, mediante la concreción del derecho a su propia jurisdicción como expresión real del acogimiento del pluralismo jurídico que exige el Derecho vigente (Faundes, 2019).

De la misma manera refleja la distancia que existe entre el discurso normativo presente en la legislación moderna, y la práctica de las instancias gubernamentales encargadas de ejecutar dicho mandato (Malik y Ballestero, 2015). En esta labor es posible identificar una tendencia común en el estudio de las sociedades postcoloniales a acudir a sociedades imaginadas, como totalidades orgánicas con criterios de unidad y homogeneidad (Sanjinés, 2009). Esta perspectiva tiende a omitir la influencia de las fuentes materiales como el Derecho impuesto, la religión y otras variables que determinan el nivel de acogimiento de una norma consuetudinaria en la población (Espinoza, 2020). Dentro de estos factores confluyen la situación actual del pueblo aymara, expuesto a condiciones de pobreza y marginalidad, construyen un espacio de desestructuración de sus pautas de solidaridad y reciprocidad al interior de las comunidades (CEPAL, 2014).

Hemos seleccionado dos casos de conflictos en la población aymara que se han resuelto en los tribunales nacionales, estos dan cuenta de diferentes formas en que se conjuga la costumbre respecto de la situación de niños aymaras, estos son una muestra que según nuestro parecer justifican los argumentos previamente desarrollados.

\section{Negación del Derecho propio y pautas de crianza aymaras}

El caso de la pastora Aymara G.B.B., si bien no tiene como sujeto principal la figura de un niño, sino a su madre, nos permite contrastar las pautas de ponderación que desarrollan los tribunales en materia de crianza y estructura familiar en un contexto cultural diversos. Finalmente, el alcance de lo resuelto dará cuenta cómo sus efectos se vinculan directamente a la materia en estudio. El proceso comienza inicialmente como una investigación por los delitos de parricidio, abandono de menor simple, obstrucción a la investigación e incesto. En este la madre resultará condenada por el delito de abandono de menor con resultado de muerte según sentencia pronunciada por el Tribunal Oral en lo Penal de Arica en el 2010.

El proceso permite analizar la conjugación de todas las variables al exponer la labor de identificación y valoración de un Derecho propio aymara en materia de pautas de crianza y estructuras familiares por parte del Tribunal. También nos exhibe la diversidad de criterios aplicables en la función judicial, ya que el conflicto atraviesa todas las instancias de la estructura judicial desde un tribunal 
de primera instancia hasta su revisión en el sistema interamericano de Derechos Humanos. En lo particular, enfocaremos nuestro estudio a la línea que hemos propuesto, es decir, su relación con el derecho a la identidad cultural, Derecho propio y niños indígenas.

En cuanto a los hechos, los antecedentes fundamentales indican que el 2007 la pastora junto con su hijo de 3 años y 11 meses realizaban labores de pastoreo propias de etnia aymara para un tercero a cambio de una remuneración. Según el relato de la madre el niño se le extravió mientras ella iba a buscar a unos animales, luego de buscarlo hasta la noche volvió al hogar debido a las condiciones de oscuridad y bajas temperaturas. Al día siguiente continuó la búsqueda sin resultados, por lo que recurrió a buscar ayuda al pueblo más cercano situado a 17 kilómetros. En diciembre de 2008 es encontrado el cuerpo sin vida del niño, durante este tiempo la madre estará privada de libertad, en el 2010 se dictará la sentencia condenatoria.

En lo sustancial el fallo presume el abandono del menor por parte de la madre, los fundamentos valorativos se sostienen en que la madre tuvo una conducta anómala para una madre, independiente de su origen étnico, o bien, resaltando que se trata de una conducta que aún en el contexto de la estructura social aymara también es merecedora de reproche. Ambos argumentos contienen una valoración acerca de las pautas de crianzas aymara a partir de una ponderación particular de las pericias antropológicas presentadas en el juicio.

Resulta contradictorio en el proceso la ausencia de un análisis desde la perspectiva de los derechos del niño indígena, esto hubiese permitido fijar un parámetro del deber ser normativo para resignificar las prácticas de la madre en relación con el menor. Como hemos indicado, los estándares del sistema interamericano han establecido un derecho preferente para los niños indígenas menores a regularse por su propio Derecho, esto justificaría el formarse en el contexto de su cultura y sus pautas de crianza.

Es preciso recordar que en el caso de la etnia aymara los niños son considerados como parte integral del todo, lo que permite su incorporación a las actividades colectivas como personas pequeñas (Liebel y Saadi, 2012: 128). Esto es posible relacionarlo con la funcionalidad de la familia considerada como unidad de producción para la ayuda mutua interfamiliar y el manejo de los recursos productivos. Esto definirá sus pautas de crianza y fijará roles al interior del grupo (Gavilán, 1995).

En contrario, el Tribunal descartará este elemento concluyendo que no es posible asociar el conflicto a la costumbre aymara, justificando mediante un razonamiento superficial que dejar a un niño en un lugar solitario no está asociado con normas consuetudinarias. Esto pese a que la defensa hará llegar pruebas de la costumbre de las mujeres aymaras de pastorear con niños, incluso resaltando la importancia que este aspecto tiene para el aprendizaje de la infancia en su medio cultural (Tribunal Oral Penal de Arica, 2010: cons. $14^{\circ}$ ).

Proponemos que una ponderación adecuada dentro del marco jurídico vigente debiera iniciarse y mantenerse exclusivamente en el Derecho consuetudinario aymara. Desde ahí definir si el actuar constituye un abandono sancionable, considerando las sanciones asignadas desde sus costumbres a dicho acto. Teniendo además presente la desestructuración que la modernidad ha producido en muchos de estos patrones, donde la solidaridad comunitaria en muchos casos ha desaparecido o ha mutado frente a la asimilación.

La sentencia no da cuenta de un juicio en el que se involucra una persona con pertenencia indígena, salvo para declarar que el juicio no involucra la costumbre como razón para no considerar el Convenio 169. La ausencia de una debida consideración de estos factores resulta vulneradora de las pautas emanadas de los instrumentos de Derechos Humanos y conlleva responsabilidad internacional para el Estado por incumplimiento de sus deberes.

El 15 de mayo del 2011 se presentará ante la Comisión Interamericana de Derechos Humanos una denuncia contra el Estado de Chile por la vulneración de varios derechos de la Convención Americana de Derechos Humanos, entre estos su artículo $\mathrm{N}^{\circ} 19$ (derechos del niño). El 21 de noviembre ante este mismo organismo se acordará el Informe $N^{\circ} 138 / 18$, de Solución Amistosa entre G.B.B. y C.B.B. y el Estado de Chile.

Este acuerdo contiene ciertas medidas de reparación; entre estas el Estado reconoce su responsabilidad por las graves violaciones a los Derechos Humanos de la víctima. Asimismo, como medida de no repetición, se compromete a desarrollar un programa de capacitación de 
cobertura nacional para los funcionarios públicos, con especial mención del poder judicial, el Ministerio Público, la Defensoría Penal Pública, Carabineros, entre otros, orientado al acceso a la justicia y protección de niños indígenas y respeto por los estándares interamericanos en materia de Derechos Humanos e infancia indígena.

\section{Una interpretación intermedia, Derecho occidental en clave cultural}

Ante un Tribunal de Familia de primera instancia se inició de oficio un procedimiento de protección en favor de tres menores. En otra causa seguida ante el mismo tribunal, se logró advertir que sus derechos podrían encontrarse vulnerados por negligencia de su madre, ya que estos no se encontraban registrados ante las instancias estatales, por tanto, carecían de documentos de identidad y como consecuencia tampoco se encontraban insertos dentro del ciclo educacional obligatorio en Chile (Tribunal de Familia de Iquique, 2008).

Entre los antecedentes de la defensa se indicará que la madre es oriunda de una localidad situada en sectores rurales aislados en que habitan comunidades indígenas aymaras a la que pertenece, agregando que en estos lugares no existe acceso a red social alguna, estos factores habrían impedido la obtención de documentos de identidad para ella y sus hijos, razón por la que no accedieron a tiempo a los sistemas de salud y educación.

El tribunal de primera instancia resolverá el asunto, disponiendo el ingreso definitivo de los niños a hogares de custodias diferenciados según el sexo de los menores debido a la situación de grave vulneración de sus derechos. La madre de los menores se alzará presentando un Recurso ante la Corte de Apelaciones respectiva, en esta instancia el tribunal de alzada confirmará el fallo, sin modificaciones. En contra de esta última decisión, la madre recurrirá de casación en el fondo ante la Corte Suprema solicitando la invalidación y la dictación de una sentencia de reemplazo.

Entre sus principales argumentos destacará que se trata de una familia perteneciente a la etnia indígena aymara, que la unidad doméstica vivió hasta hace muy pocos años en un lugar apartado de los centros urbanos, resaltando que se trata de una familia con costumbres de crianza ancestrales reconocidas por el Estado en la Ley $\mathrm{N}^{\circ} 19.253$ y en el Convenio 169.

La Corte Suprema acogerá el recurso, revocando el fallo y dictando otro en reemplazo, en esta el tribunal extenderá su pronunciamiento a cuestiones asociadas no solo a fundamentos normativos, sino a la existencia de principios complementarios para interpretar la norma. En particular, se remitirá a la relación entre el principio de identidad cultural y el interés superior del menor.

En esta secuencia, el Tribunal superior realizará un ejercicio de interpretación intermedia, es decir, aplicará la normativa general, en particular el interés superior del niño pero interpretado en clave cultural orientándolo al respeto por la identidad cultural. Esta metodología si bien no logra alcanzar el estándar de respeto pleno que orienta a la aplicación de un Derecho propio, logra salvar la ponderación de asimilación desarrollada en las instancias inferiores, dándole una connotación particular más que global, indicando:

Que de conformidad con lo dispuesto en el artículo $3^{\circ}$ de la Convención de los Derechos del Niño, en todas las medidas concernientes a los niños deben los tribunales de justicia tener como consideración primordial, el interés superior del niño y, ciertamente, ello impone a los jueces el deber de atender a las costumbres y forma de vida del grupo social a que pertenecen. En la especie, la situación que ha motivado estas actuaciones dice relación con una familia aimara que vivió hasta hace poco tiempo en un poblado de la precordillera; en tales circunstancias, su relación con el Estado claramente no podría ser de la entidad que puede esperarse de las personas que no integran comunidades minoritarias, razón por la cual el juicio relativo a la afectación a los derechos de los niños también debe hacerse desde esta perspectiva. Por tal razón no es posible descalificar a la madre por no haber integrado a los niños a las redes sociales (Corte Suprema, 2009: cons. 4).

Esta es la razón por la que se ha señalado que la identidad cultural formaría parte de un núcleo 
central en la Convención de Derechos del Niño, así su importancia radica en que actúa poniendo un límite a la soberanía estatal impidiendo una actuación discrecional. En definitiva, se plantea un diálogo sincrético, al considerar los hechos resguardando y justipreciando los valores prioritarios sacrificando incluso variables derivadas de la técnica jurídica (De Lucas, 1998).

A diferencia del caso anterior (que solo llegará a instancias menores), la Corte Suprema en sus fundamentos normativos releva su orientación a las normas adecuadas, indicando que:

... [ ] En este contexto y considerando que la madre de los niños pertenece a la etnia aimara, ha de tenerse presente lo dispuesto en el artículo $1^{\circ}$ de la Ley $\mathrm{N}^{\circ} 19.253$ que, recogiendo el principio constitucional enunciado, dispone que es deber del Estado respetar y proteger su cultura; a lo que cabe agregar que, de acuerdo a lo señalado en el artículo 30 de la Convención sobre los Derechos del Niño, publicada el 14 de agosto de 1990, los niños pertenecientes a una minoría étnica tienen derecho a tener su propia vida cultural y a emplear su propio idioma (Corte Suprema, 2009: cons. tercero).

En definitiva, este derecho a la identidad cultural otorga un contexto condicionando a la interpretación que los jueces conceden al principio del interés superior, dirigiéndolo a un espacio en que se debe considerar las costumbres propias. Reiteramos, que la solución planteada no responde plenamente a las pautas exigidas por la estructura jurídica vigente, cuya consideración debieran derivar a ponderar la correspondencia de los actos en el contexto exclusivamente consuetudinario para evaluar la corresponsabilidad parental de la madre con los hijos, con el límite de respetar los Derechos Humanos que como hemos resaltado nos devuelven reforzadamente a la misma conclusión.

\section{Reflexiones a modo de cierre}

El Derecho actual funciona desde el paradigma del acogimiento de la diversidad cultural que se materializa en el reconocimiento del derecho a la identidad cultural, este incorpora distintas dimensiones de garantías, entre estos el reconocimiento del Derecho consuetudinario propio para resolver los conflictos de los pueblos indígenas. En este escenario los niños indígenas reciben una protección reforzada desde los instrumentos jurídicos superiores por su doble condición de niño e indígena. Esto favorece la eficacia jurídica de su garantía, a lo menos desde el Derecho fijado para nuestro tiempo.

Esta claridad normativa no logra conferir certeza jurídica, como consecuencia no se logran cumplir los fines que en ella se promueven. Reconocemos una diversidad de factores como impulsores de esta realidad, en el centro de esta complejidad descansa el acogimiento desigual de un pluralismo jurídico y la ausencia de una judicatura propia indígena. Lo anterior, deriva en que la identificación de lo consuetudinario para resolver conflictos se conforme como una labor de traducción de cuestiones complejas y distantes para las competencias de la función judicial.

Como consecuencia es posible observar una disparidad general entre los criterios de los tribunales a nivel nacional, cuestión que se profundiza entre la jurisprudencia de instancias inferiores y los tribunales de última instancia como con los del sistema interamericano. En estos últimos pareciera existir un mayor conocimiento del alcance de las disposiciones normativas superiores, lo que deriva en una mayor disposición a respetar y aplicar el Derecho propio indígena.

En definitiva, se observa una distancia entre el sentido teleológico de la norma y la forma como se ejecuta el mandato, aun en espacios de protección reforzada como el estudiado. Esto no resulta superficial, en cuanto compromete la responsabilidad del Estado frente al incumplimiento de los compromisos contraídos como pudimos observar en los casos estudiados. Los antecedentes relevan la necesidad de concretar el derecho a la jurisdicción propia como mecanismo directo para garantizar la identificación de sus propias costumbres en una población como la aymara, cuya dinámica de constantes cambios hace compleja dicha operación.

La situación de la niñez indígena aymara cuyas garantías se encuentran particularmente reforzadas, conceden claridad respecto del nivel de eficacia del Derecho vigente permitiéndonos reconocer una práctica de resistencia al cumplimiento normativo. Esto conlleva a la no 
aplicación del Derecho propio, o bien a la constante filtración de criterios culturalmente ajenos como vestigios de una política de asimilación que no se retira plenamente, reflejando que el Derecho es un ejercicio que se extiende más allá de lo exclusivamente normativo.

\section{Referencias Citadas}

Bobbio, Norberto

2007 Teoría General del Derecho, Editorial Temis, Bogotá, p. 194.

Cea, José Luis

2012 Derecho Constitucional Chileno, Tomo II, Ediciones Universidad Católica.

\section{CEPAL}

2014 Los pueblos indígenas en América Latina: avances en el último decenio y retos pendientes para la garantía de sus derechos. Santiago, p. 5.

Clavero, Bartolomé

2009 Derecho Indígena y Constitucional en América, Siglo XXI Editores, México.

Contesse, Jorge

2013 “LLa última palabra? Control de convencionalidad y posibilidades de diálogo con la Corte Interamericana de Derechos Humanos". Disponible en: http://www.law. yale.edu/documents/pdf/sela/SELA13_Contesse_CV_ Sp_20130401.pdf (28 de marzo del 2016).

Comité de los Derechos del Niño

2009 Observación General Nº 11.

Cruz, Elisa

2019 "El Derecho Indígena como impulsor del Pluralismo Jurídico en el Derecho Mexicano". En: Diálogo Andino, 59: 132-133.

De Lucas, Javier

1998 "La Sociedad Multicultural. Problemas Jurídicos y Políticos", En: Derecho y Sociedad M. Añon et al. (coords.). Tirant Lo Blanch, Valencia, pp. 19-47.

De Trazeignes, Fernando

2018 Derecho y Postmodernidad, Editorial Jurídica Grijley, Lima.

Del Real, J. Alberto

2013 El derecho a la identidad cultural: Criterios de fundamentación. En: Derechos y Libertades, 29, pp. 195-196.

Diez Picazo, Luis

1993 Experiencias Jurídica y Teoría del Derecho, Editorial Ariel, Barcelona, p. 8.

Espinoza, Álvaro

2016 "La Invisibilidad Jurídica de la Familia Andina en el Norte de Chile", en: Revista de Derecho de la Universidad Austral, 29: 1, pp. 120-130.

Espinoza, Álvaro

2017 "El Reconocimiento del Derecho Consuetudinario Indígena como Derechos Humanos: su estado en el Derecho chileno", en: Revista Cadernos de Dereito Actual, 8, pp. 413-437.

Espinoza, Álvaro

2020 "La fijación de la costumbre indígena Aymara en un contexto de translocalización. una propuesta desde de la teoría de los principios en el Derecho", en: Interciencia, 45: 1, pp. 49-57.
Faundes, Juan Jorge

2019 "Derecho fundamental a la identidad cultural de los pueblos indígenas: un nuevo paradigma en la defensa penal indígena en Chile frente al Estado de Derecho hegemónico", en: Izquierdas, 45, pp. 52-53.

Fernández, Marcelo

2000 La Ley del Ayllu, práctica de jach'a justicia y jiskà justicia (justicia menor y justicia mayor) en comunidades aymaras, Programa de Investigación Estratégica en Bolivia, La paz, p. 2.

Gavilán, Vivian

1995 "Una aproximación a las relaciones de género entre los aymaras del norte de Chile", en: Temas Regionales 2, pp. 21-34.

González, Sergio

2002 Chilenizando a Tunupa. La Escuela Pública en el Tarapacá Andino 1880-1990, Colección Sociedad y Cultura, Ediciones de la Dirección de Bibliotecas, Archivos y Museos, Santiago, p. 292.

Gunderman, Hans

2019 Comunidad Indígena, espacio andino y transformación estructural en Tarapacá y Arica. Ensayo de interpretación sociohistórica, en Camachisca Estudios sobre Derecho comunitario indígena en la zona andina, Espinoza A. et al. (edit.), Editorial de la Universidad de Tarapacá, p. 275.

Guzmán, Alejandro

1987 "El régimen de la costumbre en las codificaciones de Hispanoamérica y España emprendidas durante el siglo XIX", en: Revista de Estudios Históricos y Jurídicos, 12, pp. 237-254.

Pérez Luño, Antonio

2007 Trayectorias contemporáneas de la Filosofía y la Teoría del Derecho, Editorial Tébar, Madrid, pp. 18-19.

Haberle, Peter

2006 Aspectos constitucionales de la identidad cultural. En: Derechos y Libertades, 14: 91.

Liebel, Manfred y Saadi, Iven

2012 La participación infantil ante el desafío de la diversidad cultural. En: Desacatos, 39: 128.

Malik, Beatriz y Ballesteros, Belén

2015 La construcción del conocimiento desde el enfoque intercultural, en: Diálogo Andino 47, pp. 15-25.

Núñez, Constanza

2015 "Bloque de Constitucionalidad y control de convencionalidad en Chile: avances jurisprudenciales". En Anuario de Derechos Humanos, 11: 159.

Sanjinés, Javier

2009 Rescoldos del pasado, Conflictos culturales en sociedades postcoloniales, Fundación PIEB, Programa de Investigación Estratégica, La Paz, p. 47.

Santos, Boaventura de Souza

1988 "Droit: une carte de la lecture dèformèe. Pour une conception post-moderne du droit", en: Droit et Societe, 10, p. 382 
Veloso, Paulina

1998 "Nuevos Principios del Derecho de Familia en Función, Principalmente de la Normativa Internacional que Emana de los Tratados de Derechos Humanos", en: Revista de Derecho de la Universidad Católica de Valparaíso, XIX, p. 56.

Valenzuela, Mylene

2016 "Niños y niñas indígenas en la jurisprudencia de la Corte Interamericana de Derechos Humanos", en: Revista de Derecho Universidad Católica del Norte, 23: 2, pp. 211-240.

\section{Jurisprudencia citada}

Sentencia Corte de Apelaciones de Antofagasta 2006, en delito de parricidio, Rol 168-2006 de 24 de noviembre.

Sentencia Tribunal de Familia de Iquique 2008, causa RIT P 9972008 del 31 de diciembre.

Sentencia Tribunal Oral Penal de Arica 2010, RIT 221-2009 de 15 de abril.

Sentencia Corte de Suprema de Chile 2009, Rol 3784-2009 de fecha 10 de septiembre.

Sentencia CIDH 2007, caso del Pueblo Saramaka. Vs. Surinam. Excepciones Preliminares, Fondo, Reparaciones y Costas. Sentencia de 28 de noviembre.
Sentencia Tribunal Oral Penal de Arica 2010, delito de abandono de menores con resultado de muerte, de fecha 11 de octubre.

Sentencia CIDH 2010, caso Comunidad indígena Xákmok Kásek con Paraguay. Fondo, Reparaciones y Costas. Sentencia de 24 de agosto.

Sentencia CIDH 2010, caso Chitay Nech y otros con Guatemala. Excepciones preliminares, Fondo, Reparaciones y Costas, de 25 de mayo.

Sentencia CIDH 2012, caso masacres de Río Negro con Guatemala. Excepciones preliminares, Fondo, Reparaciones y Costas. Sentencia de 4 de septiembre.

Sentencia CIDH 2014, caso de los Pueblos Indígenas Kuna de Madungandí y Emberá de Bayano y sus Miembros Vs. Panamá. Excepciones Preliminares, Fondo, Reparaciones y Costas, de 14 de octubre de 2014, párr. 167.

Comisión Interamericana de Derechos Humanos 2018, Informe $N^{\circ}$ 138/18, Petición 687-11, Solución Amistosa G.B.B. y C.B.B. 21 de noviembre.

Sentencia Corte Suprema 2017, Rosenmann Morales y otro con Servicio de Registro Civil e Identificación, Rol: 4732-2017, de fecha 4 de mayo. 
